\title{
Integrated Thermal Management Simulation: Evaluating the Effect of Underhood Recirculation Flows on AC-System Performance
}

\author{
Zhu Wang ${ }^{1}$, Kristian Tuszynski ${ }^{2}$, Hubertus Tummescheit ${ }^{2}$, Ales Alajbegovic ${ }^{1}$ \\ 1) Exa Corporation \\ Livonia, MI 48152, USA \\ 2) Modelon $A B$ \\ Ideon Science Park, Lund, Sweden
}

ales@exa.com

\begin{abstract}
Presented is a model for the simulation of the interaction between the airflow and the AC-system. Demonstrated is 1) a successful coupling of flow solver (PowerFLOW 4.1) with the Modelica-based Dymola system tool and the AirConditioning Library, making use of the previously validated underhood-environment, and 2) the importance of a careful design of the underhood flow for the AC-system performance. The validity of the developed simulation capability is tested by successful comparison with the available experimental data for the condenser at the given operating conditions. Shown is the potential for the analysis of the flow details and structures affecting the condenser performance like airflow recirculation.
\end{abstract}

Keywords: HVAC simulation; underhood flow; simulator coupling

\section{Introduction}

Vehicle can be seen as a system composed of multiple sub-systems. One such subsystem is the ACsystem which is used to maintain passenger comfort. A key component of the AC-system is the condenser. The condenser is used to condensate the refrigerant by extracting the heat from the refrigerant to the airflow. For the operation of the AC-system is very important that the refrigerant condensation is completed at the outlet from the condenser. It is possible that this does not occur in cases of adverse airflow conditions in the proximity of the condenser. For example, airflow recirculation can cause local temperature peaks and consequent reduction of the condensation rate.
The ability to predict such behavior and if possible avoid it is of great importance for the design of vehicle cooling airflow performance. Srinivasan et al. [1] presented an omni-tree meshing technology for rapid mesh generation for Navier-Stokes solvers. The cooling airflow simulations using Navier-Stokes solvers coupled with heat exchanger calculations for passenger cars were presented by [1], [2], [3], and for trucks by [4], [5], [6].

Fortunato et al. [7] used the Lattice-Boltzmann Equation (LBE) solver for the cold flow simulation over the entire car including the underhood and a NavierStokes solver for the underhood flow. The velocity field on the entrance surfaces into the underhood area calculated by the LBE solver was used as the inlet boundary condition to the Navier-Stokes solver calculation. Fully coupled simulations between the LBE solver and a system simulation tool for the heat exchanger were presented by Alajbegovic et al. [9], [10]. A detailed validation of the cooling package using coupling with the AMESim system simulation tool was shown in [11]. The simulation capability presented here used the same experimental data for the validation of the developed methodology.

\section{Simulation Methodology}

The presented simulation methodology is based on coupled simulations between the flow and system solvers. Therefore, the following three major simulation components are:

1. Flow modeling with the Lattice-Boltzmann Equation solver

2. Dymola AC model 
3. Automatic coupling between the flow solver and Dymola

\subsection{FLOW MODELING}

The flow simulation is performed using the LatticeBoltzmann Equation (LBE) based solver. The Lattice-Boltzmann solvers are numerically very efficient, accurate and robust. The numerical efficiency allows handling of lattices with very large element (or voxel) counts. It is quite normal to have 100 million voxels for a full vehicle analysis. This is required to resolve an as large as possible span of turbulence scales and in this way increase the accuracy of the predictions.

Properties of the Boltzmann equation allow for an improved treatment of fluid interactions with the wall surface. Surface elements (or surfels), are designed as active elements that interact with the neighboring lattice elements. The combination of both large lattices and dynamic surface treatment allow accurate representation of surfaces without the need for geometry simplification.

Earlier use of Lattice-Boltzmann equation in fluid flow simulations was done by Frisch, Hasslacher, \& Pomeneau [12]. After that, significant efforts were made to develop Lattice-Boltzmann flow solver [13], [14], [15]. Turbulence effects are modeled using a modified $k-\varepsilon$ model based on the original RNG formulation [16], [17]. This LBE based description of turbulent fluctuation carries flow history and stream information, and contains high order terms to account for the nonlinearity of the Reynolds stress [18]. This is contrasted with typical Navier-Stokes solvers, which tend to use the conventional linear eddy viscosity based on the Reynolds stress closure models. Turbulence and temperature equations are solved on the same lattice using a modified LaxWendroff-like explicit time marching finite difference scheme.

Simulations presented in this work were performed using the flow solver described in the following references [19], [20], [21], [22], [23].

\subsection{DYMOLA MODELING}

Dymola (Dynamic Modeling Laboratory) is a multiengineering software package suitable for modeling of a large variety of physical and engineering systems, such as mechanical, electrical, hydraulic, chemical, thermodynamic, control, etc., see [24]. Based on the open modeling language Modelica [25], [26], Dymola supports hierarchical model composition, libraries of truly reusable components, domainspecific connectors taking care of mass- and energy conservation on the system level and non-causal connections. A typical representation of the graphic user interface is shown in Figure 1.

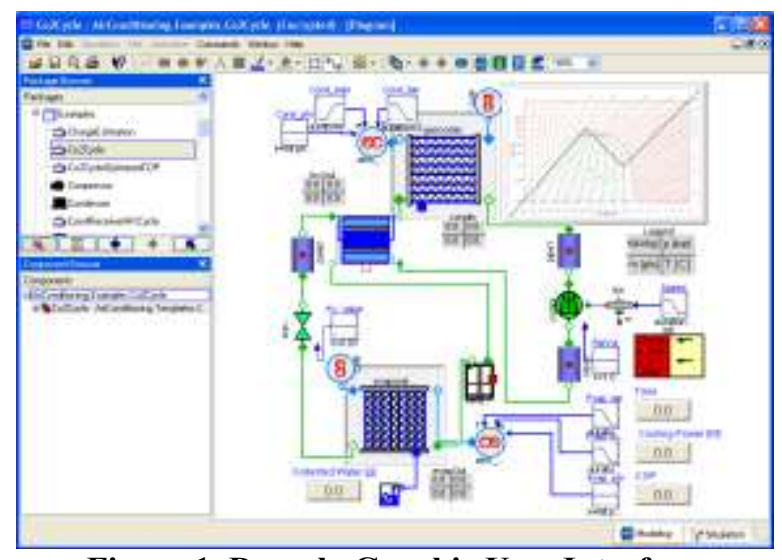

Figure 1. Dymola Graphic User Interface

Model libraries are available in many engineering domains. The heat exchanger models used in this paper are from the AirConditioning Library developped by Modelon AB (see [27], [28]). The Library has been validated in many industrial projects (e.g. [28]) and before commercialization in many years of research use at DaimlerChrysler and TU HamburgHarburg. The AirConditioning library was selected as the preferred AC-systems tool by Audi, BMW, Daimler and Volkswagen and their suppliers in 2004. The condenser model used in this paper is built based on the latest AirConditioning Library 1.7 (ACL). An example of the user interface for a horizontal flow microchannel flat tube condenser from ACL is shown in Figure 2. 


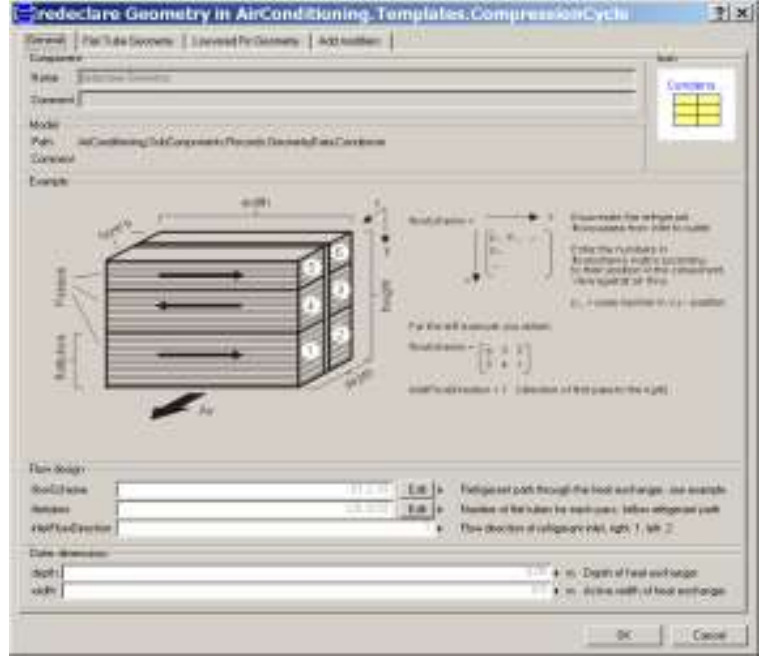

Figure 2. Dymola condenser model from the AC library

\subsection{COUPLING PROCESS}

The PowerFLOW and Dymola two-way coupling is implemented via an automated process using scripts. The coupling process involves the extraction and exchange of flow data distributions on each of the heat exchanger inlet and outlet surfaces. PowerFLOW provides the cooling air velocity and temperature field, and Dymola calculates the distribution of the heat source and provides the heat flux distribution back to PowerFLOW. The coupling process is also described in Figure 3.

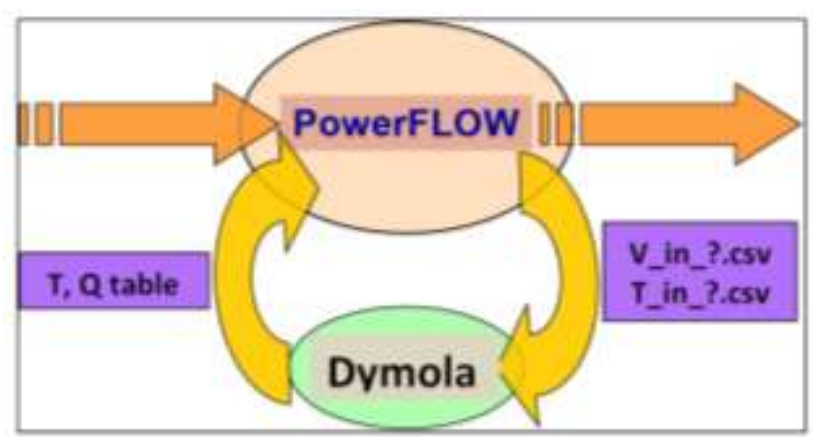

Figure 3. General two-way coupling scheme

In further detail, the coupling process between the flow solver and Dymola is realized by the table reread functionality of PowerFLOW shown in Figure 4 , and by polling for new data on the Dymola side. PowerFLOW treats the heat exchangers as porous media with heat release per volume, whereas in the Dymola and the ACL, the interaction is through discretized surfaces represented as connector variables.
Before flow simulation starts, the Dymola program "dymosim" is executed through a batch process. At each coupling step during the simulation, a coupling script is executed. The coupling script reads the description of each porous medium in the pmspec file, which contains the support information for the data extraction performed by the program exatool. Once the data are extracted (*.csv) for each heat exchanger, "dymosim" will read-in the .csv files and then generate the heat rejection table file for each heat exchanger. The flow solver calculates the flow field again once all heat exchangers table files are available. The flow solver divides these two-dimensional heat fluxes data by the thickness of the porous media to get the distribution of the volumetric heat. Once the coupling is completed, the flow solver automatically rereads the new tables. This process continues until convergence is reached for each time step.

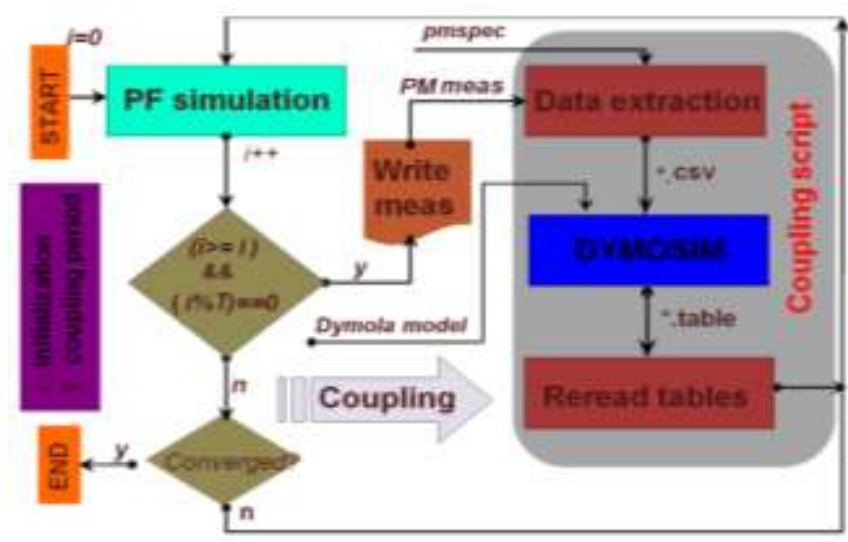

Figure 4. Flow chart of the coupling process

The output from the Dymola heat exchanger models does not require special treatment due to the uniform grid discretization. The velocity and temperature field at the inlet plane of the heat exchanger are mapped to Dymola grid uniformly.

\subsection{Validation}

The vehicle used for the validation of the coupling between the flow solver and the Modelica based simulation of the HVAC system was the Renault Scenic II, Figure 5. Shown are the vehicle, its underhood geometry and cooling package. Flow predictions provide air velocity and temperature distributions in the entire domain including the engine compartment and vehicle exterior. The details of the geometry preparation, case setup and boundary conditions can be referred to in [11]. 

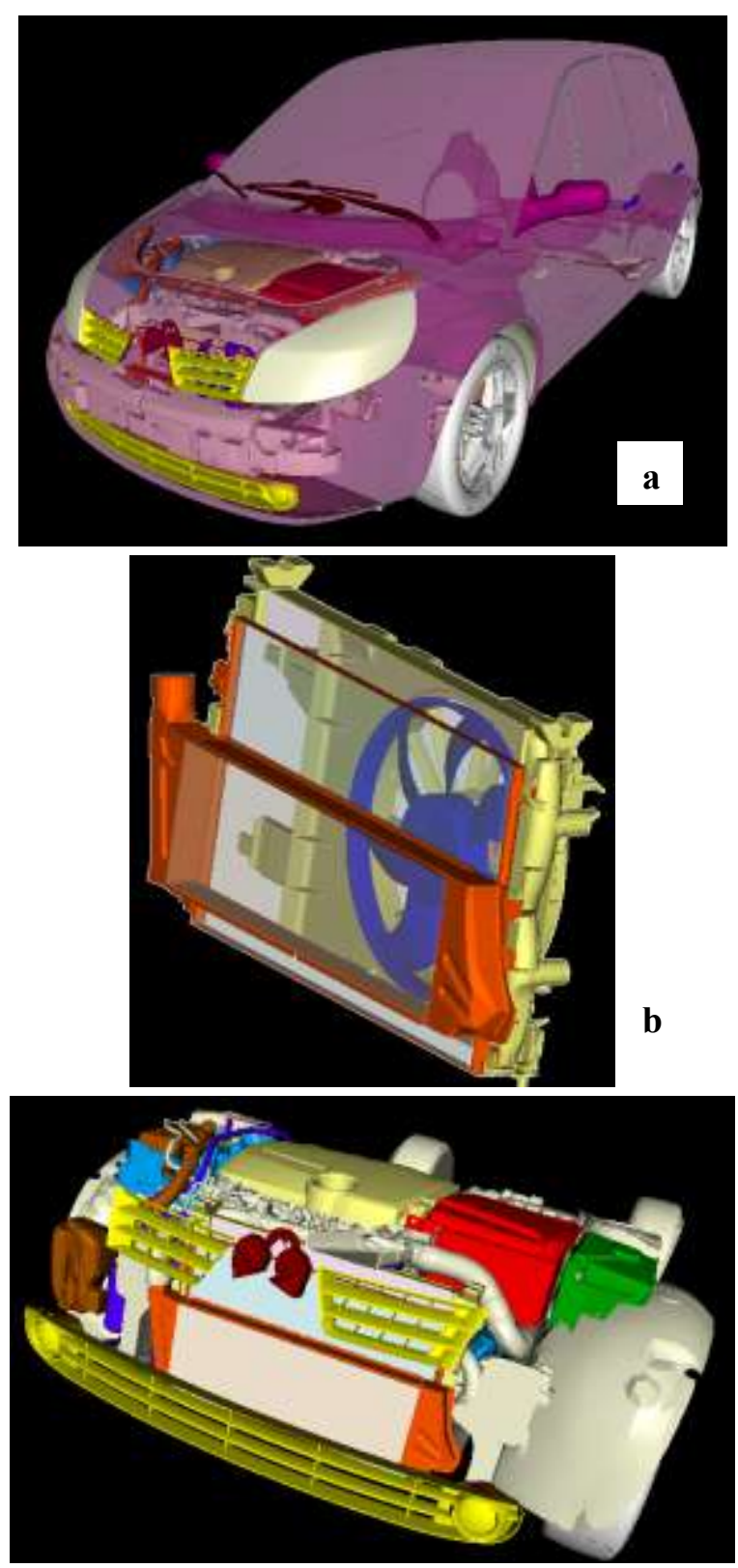

Figure 5. a.) Vehicle geometry, b.) Cooling package details and c.) Underhood geometry

Vehicle placement in the thermal wind tunnel and geometry with the nozzle profile is shown in Figure 6. Validation was focused on evaluating the condenser performance. The predicted values were compared to the measurements.

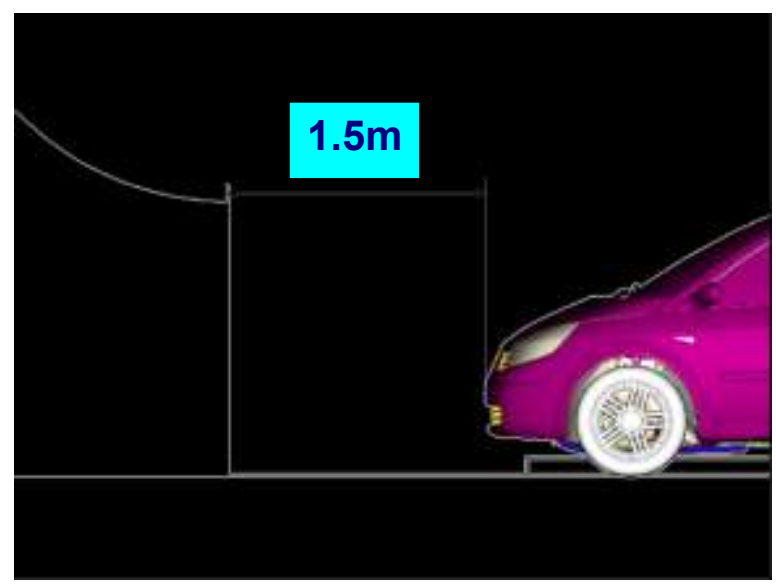

Figure 6. Vehicle in Thermal Wind Tunnel

\subsection{TESTING CONDITIONS}

Vehicle cooling package performance was measured in the thermal wind tunnel at a velocity of $40 \mathrm{~km} / \mathrm{h}$. The distance between the nozzle exit and the bumper of the vehicle was $1.5 \mathrm{~m}$. In order to prevent flow separations in the front region of the underbody, a boundary layer suction system was used extracting $0.78 \mathrm{~m}^{3} / \mathrm{s}$ of air from the suction section of the wind tunnel and returning the same amount of volume flow back to the wind tunnel downstream of the vehicle as indicated in Figure 7.

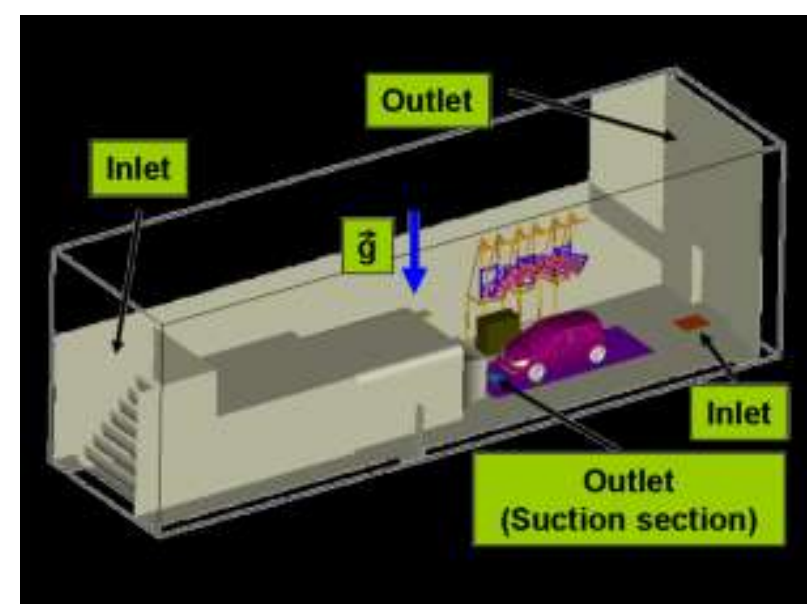

Figure 7. Overview of thermal wind tunnel 


\begin{tabular}{|c|c|c|c|}
\hline \multirow{3}{*}{ WIND } & Air Velocity & $\mathrm{km} / \mathrm{h}$ & 39.7 \\
\cline { 2 - 4 } & Air Temperature & ${ }^{\circ} \mathrm{C}$ & 44.8 \\
\hline \multirow{3}{*}{ FAN } & Voltage & $\mathrm{V}$ & 13.0 \\
\cline { 2 - 4 } & Intensity & $\mathrm{A}$ & 32.5 \\
\hline CONDENSER & Inlet Pressure & bar & 25.0 \\
\cline { 2 - 4 } & Outlet Pressure & bar & 23.6 \\
\cline { 2 - 4 } & Inlet Temperature & ${ }^{\circ} \mathrm{C}$ & 106.3 \\
\cline { 2 - 4 } & $\begin{array}{c}\text { Outlet Tempera- } \\
\text { ture }\end{array}$ & ${ }^{\circ} \mathrm{C}$ & 67.46 \\
\cline { 2 - 4 } & $\begin{array}{c}\text { Volumetric Flow } \\
\text { Rate }\end{array}$ & $1 / \mathrm{h}$ & 136.8 \\
\cline { 2 - 4 } & Heat Rejection & $\mathrm{kW}$ & 6.4 \\
\hline
\end{tabular}

Table 1. Simulation conditions

Heat exchanger conditions used during the experiments are summarized in Table 1. The numbers in denoted with italic font are used as input conditions to the simulations.

\subsection{CONDENSER MODEL}

As mentioned in the previous section, the condenser model is based on Dymola air conditioning library 1.7 and it could be one component of the HVAC system within a complete circuit loop. The condenser model utilizes the details of the condenser geometry, while the charge air cooler and radiator uses the Log Mean Temperature Difference (LMTD) approach to calculate the outlet air and outlet refrigerant temperatures based on the inlet temperatures, mass flow rates and heat transfer coefficients. The condenser consists of four passes.

The Modelica schematic of AC-system is shown in Figure 8.

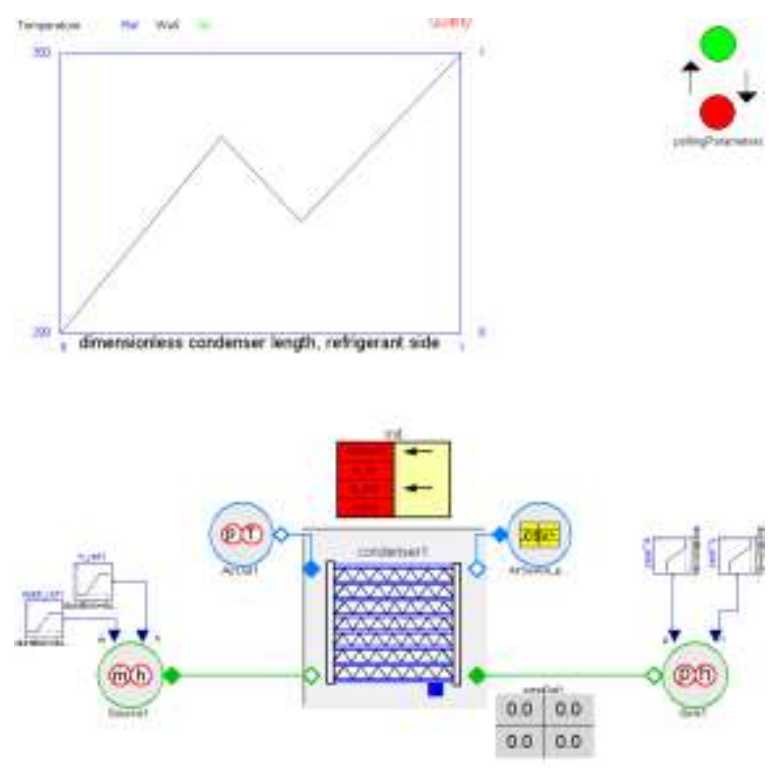

Figure 8. Dymola condenser schematic

\section{RESULTS AND DISCUSSION}

The results show good agreement between the simulations and available experimental data. The temperature field in front of the condenser is shown in Figure 9, and behind it in Figure 10. Figure 11 shows the velocity and temperature distribution at the fan middle plane. It can be observed the heating of the air by the condenser through the coupling between the flow solver and Dymola.

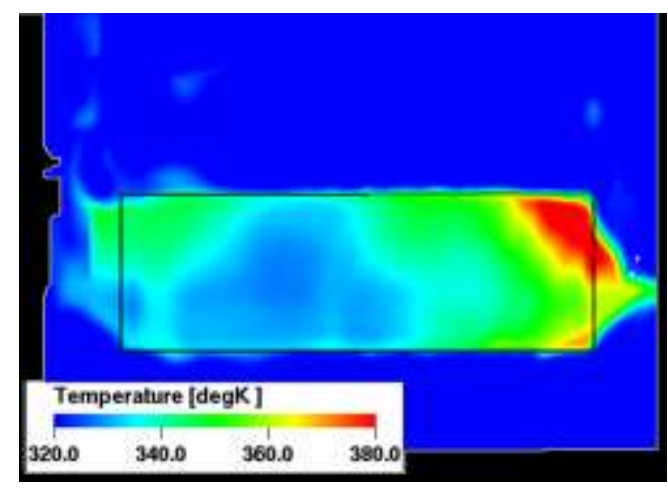

Figure 9. Temperature distribution in front of the condenser 


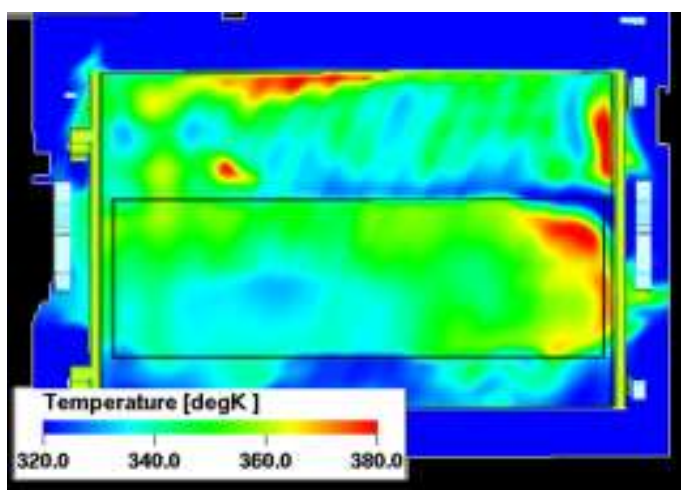

Figure 10. Temperature distribution behind condenser
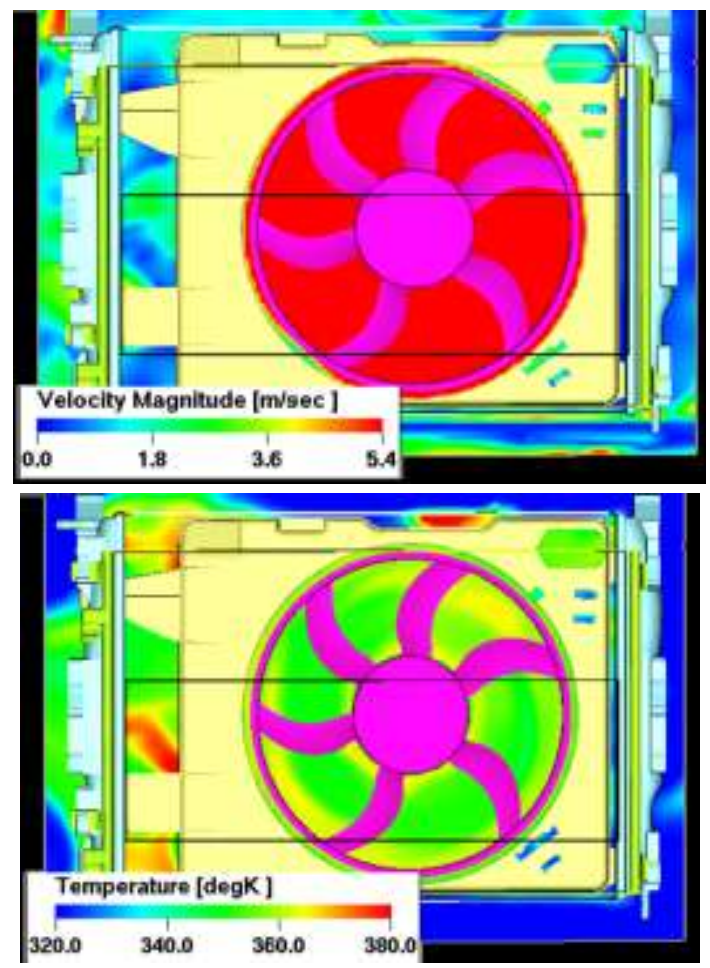

Figure 11. Velocity and temperature distribution at the fan middle plane

The details of the predicted flow velocity field within the underhood region are shown in Figure 12. Shown is the velocity field magnitude on several critical vertical planes. These locations are top left grille, fan center, center vertical plane and top right grille. High velocity at grille inlets and fan area are identified. Due to the complicated geometry, the flow within the underhood region is very complex. Recirculation, separation and local acceleration can be observed to occur almost everywhere.
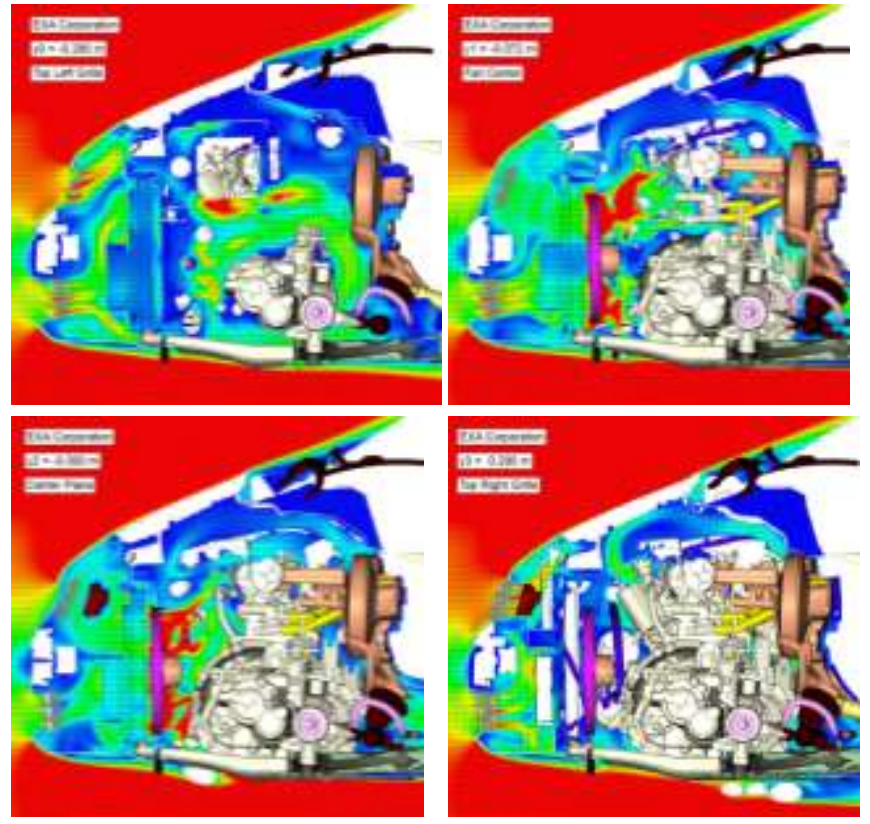

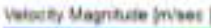

$$
2+4 \text { i } 2 \text { is }
$$

Figure 12. Velocity on y-plane in the underhood region

The details of the temperature field in the underhood region are shown in Figure 13. Shown are both streamlines and temperature field for the same vertical planes as in Figure 12. The aerodynamic and thermal behavior of cooling air can be easily captured, which can be used for the optimization of the underhood components.
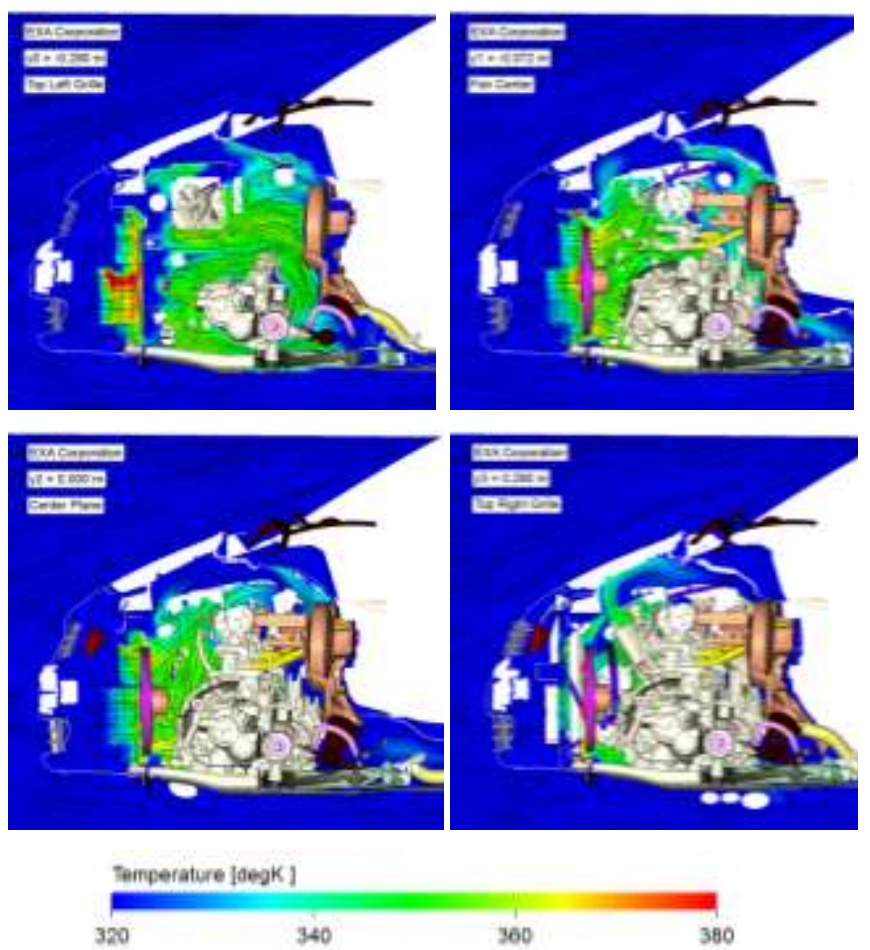
Figure 13. Temperature field on the y-plane in the underhood region

Figure 14 and Figure 15 show velocity and temperature distributions separately on several horizontal planes. These locations are bottom grille, fan center and top grilles.
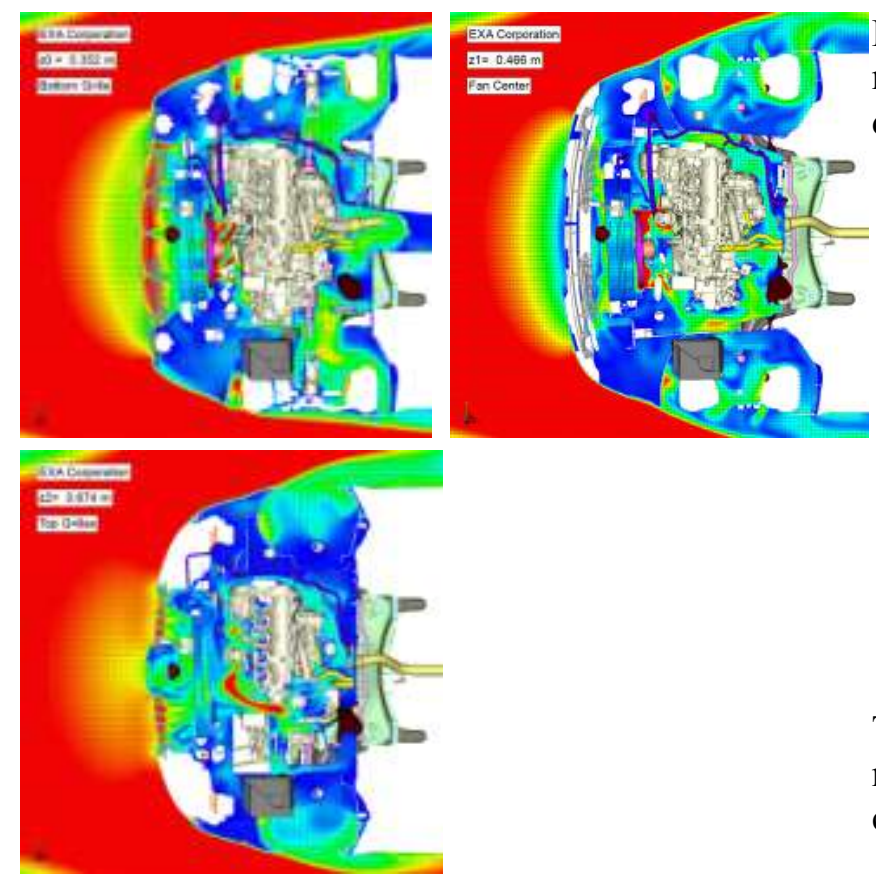

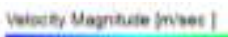

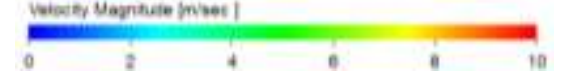

Figure 14. Velocity on the z-plane in the underhood region
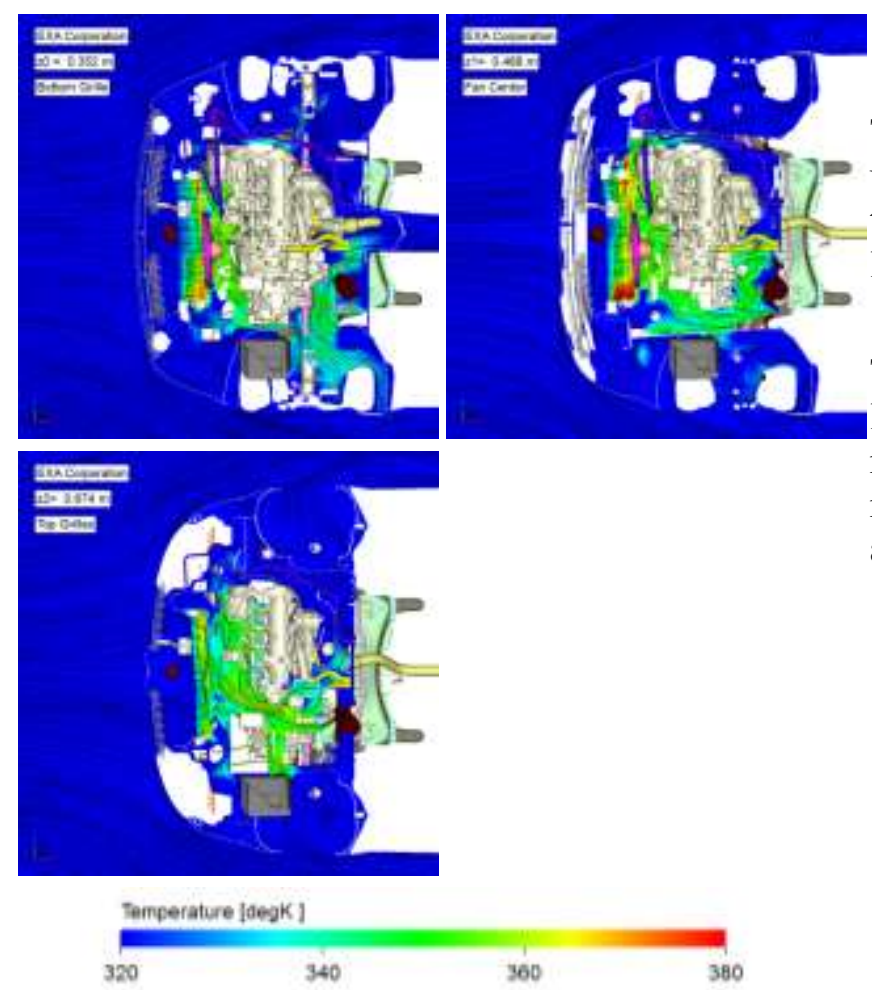

Figure 15. Temperature on the z-plane in the underhood region

The obtained results demonstrate the overall capability of the presented simulation approach where both the flow field parameters and the performance of the cooling package are evaluated.

Figure 16 shows the Dymola output for the cooling mass flow rate and the heat rejection for the condenser.
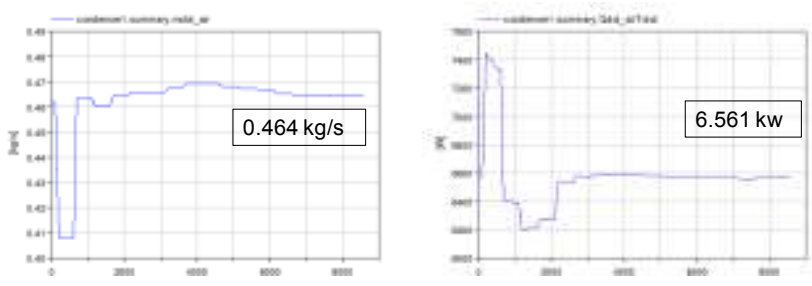

Figure 16. Dymola output: Cooling air mass flow rate and heat rejection for the condenser

Table 2 presents simulation results compared to the measured values. The predicted heat rejection for the condenser is very close to the measured value.

\begin{tabular}{|c|c|}
\hline $\begin{array}{c}\text { HEAT REJECTION } \\
{[\mathrm{kW}]}\end{array}$ & Condenser \\
\hline EXPERIMENT & 6.40 \\
\hline SIMULATION & 6.56 \\
\hline
\end{tabular}

Table 2. Heat rejection comparison

The averaged temperatures at the monitor locations use the fluid measurements close to $2 \mathrm{~cm}$ window at the corresponding locations. Figure 17 shows these locations.

The averaged fluid temperatures at the monitoring locations before and after the condenser are summarized in Table 3. Excellent correlation with the experimental data is obtained for P2R, P3FLT, P3FRT and P3FLB. 


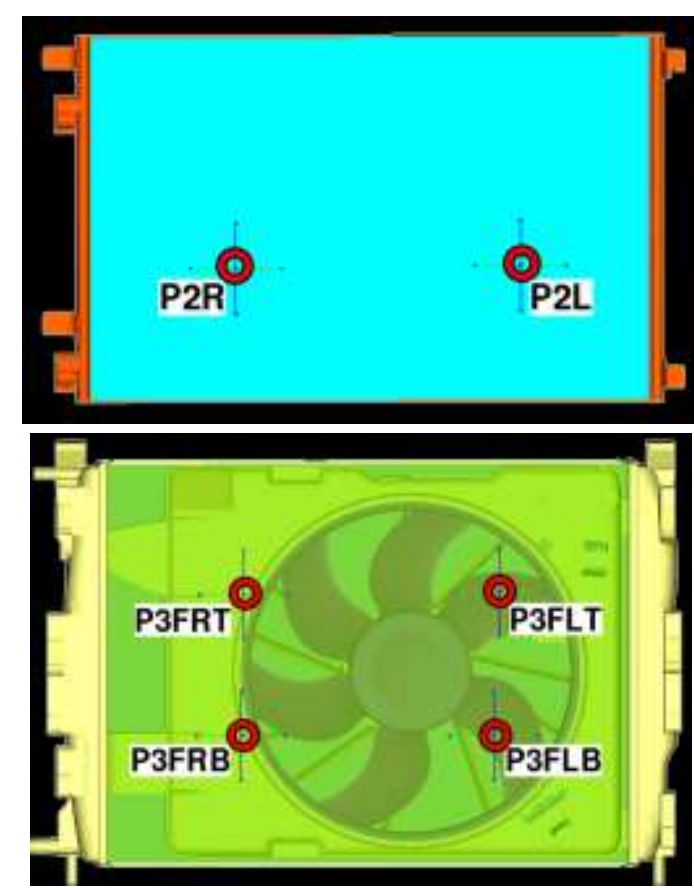

Figure 17. Locations and descriptions of the thermocouples before and after the condenser (front view)

\begin{tabular}{|c|c|c|c|c|c|c|}
\hline $\begin{array}{c}\text { TEMP } \\
{\left[{ }^{\circ} \mathrm{C}\right]}\end{array}$ & P2L & P2R & P3FLT & P3FRT & P3FLB & P3FRB \\
\hline EXP. & 78.0 & 54.5 & 58.0 & 71.7 & 67.3 & 72.4 \\
\hline PRE. & 65.8 & 56.4 & 62.1 & 74.0 & 71.2 & 61.2 \\
\hline
\end{tabular}

Table 3. Comparison between experimental and averaged predicted fluid temperature

\subsection{Study of Recirculation Airflow Effects}

To understand the interaction of the AC-System with the recirculating flow, a true coupling of a system tool and the flow solver is necessary. For the given heat exchanger case, the system tool actually discretizes the air flow across the heat exchanger face in both directions and takes inhomogeneous flows and temperatures into account. For the closed thermodynamic cycle, the hot recirculated air raises the pressure, which in turn leads to a higher temperature after the AC condenser. This positive feedback loop can either trip the high-pressure cut-off switch for the AC-system, or leads at best to severe performance degradation of the AC-circuit. The ACsystem is potentially run far away from standard conditions, close to the critical pressure in the condenser, until the compressor is switched off or regulated to minimum flow.
Figure 18 and Figure 19 shows the streamline colored by the velocity magnitude around the cooling packages. The cooling airflow in front of condenser is highly non-uniform. The air streams coming through the top grilles and bottom grilles mix with each other. Recirculation of cooling airflow can be observed right before top and bottom of the condenser. With the help of the fan nozzle, no obvious recirculating hot air downstream of the fan flows back into upstream of heat exchangers.

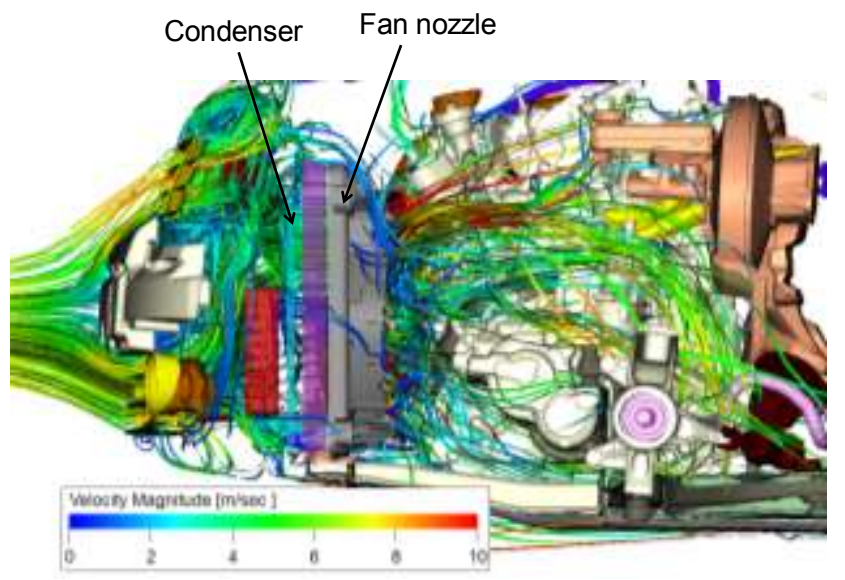

Figure 18. Streamline around heat exchangers (side view)

In Figure 19, a low velocity zone is identified at the top right corner of the condenser. This is due to the blockage of the fan nozzle at the right side. This low cooling air velocity zone causes limited local back flow and local high temperature, as can be seen clearly in Figure 20.

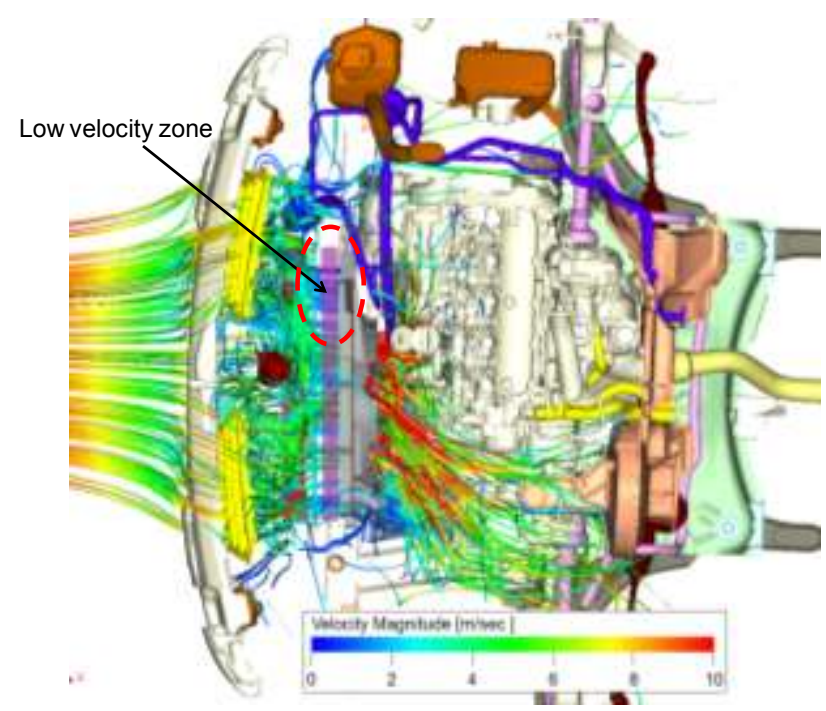

Figure 19. Streamline around heat exchangers (top view) 
With the help of a post-processing tool, the approach presented in this paper can easily help analyze the flow structure and thermal behavior of underhood cooling air. Small details like recirculation, separation and blockage can be quickly observed. This can help quick optimization of the underhood components.

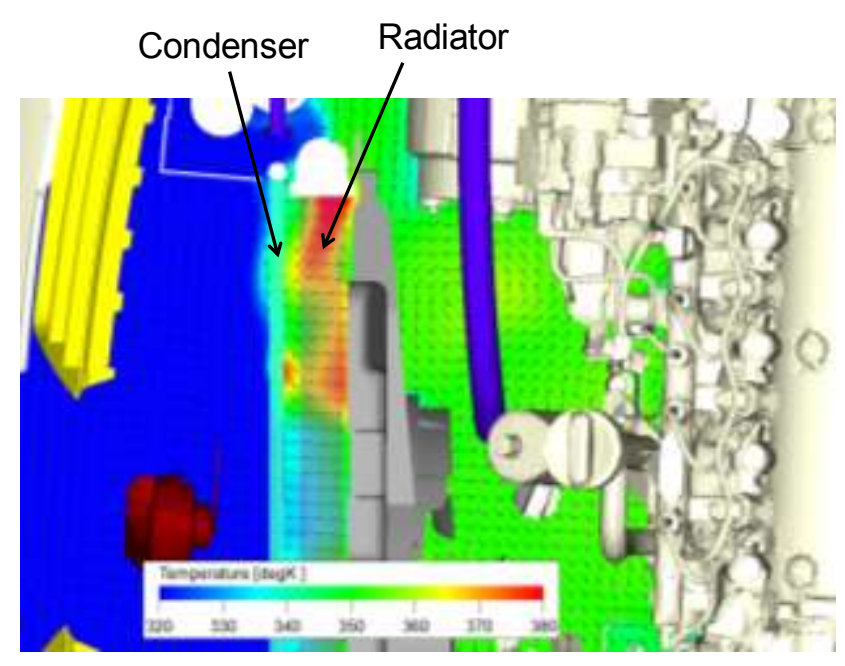

Figure 20. Local high temperature and back flow

\section{Conclusions}

Presented was the simulation methodology for the AC-system that consists of the flow solver PowerFLOW coupled with the Modelica based system simulation tool Dymola. Shown were the details of the coupling procedure that enables two way coupling between the three-dimensional flow effects and the condenser. The results demonstrate that the tightly coupled interaction of the underhood air flow with the AC-system can predict the measured heat rejection while allowing detailed analysis of the flow and temperature fields. The developed simulation methodology can be used for the studies of the vehicle air cooling performance and its optimization.

\section{References}

[1] K. Srinivasan, Z.J. Wang, W. Yuan, R. Sun, "Vehicle thermal management simulation using a rapid omni-tree based adaptive Cartesian mesh generation methodology," HTFED2004-56748, 204 ASME Heat Transfer/Fluids Engineering Summer Conference, July 11-15, Charlotte, North Carolina, USA.
[2] B. Uhl, F. Brotz, J. Fauser, U. Krueger, "Development of engine cooling systems by coupling CFD simulation and heat exchanger analysis programs," SAE 2001-01-1695.

[3] G. Seider, F. Bet, T. Heid, U. Hess, T. Klein, and J. Sauer, "A numerical simulation strategy for complex automotive cooling systems," SAE 2001-01-1722.

[4] H. Knaus, C. Ottosson, F. Brotz, W. Kuehnel, "Cooling module performance investigation by means of underhood simulation," SAE 2005-01-2013.

[5] T.P. Nobel, S.K. Jain, "A multidimensional approach to truck underhood thermal management," SAE 2001-02-2785.

[6] C.L.R.Siqueira, P. Vatavuk, M. Jokuszies, M.R. Lima, "Numerical simulation of a truck underhood flow," SAE 2002-01-3453.

[7] E.A. Costa, "CFD approach on underhood thermal management of passenger cars and trucks," SAE 2003-01-3577.

[8] F. Fortunato, F. Damiano, L. Di Matteo, P.Oliva, "Underhood cooling simulation for development of new vehicles," SAE 200501-2046.

[9] A. Alajbegovic, R. Sengupta, W. Jansen: "Cooling Airflow Simulation for Passenger Cars using Detailed Underhood Geometry," SAE 2006-01-3478, SAE Conference, Chicago, October 2006

[10] B. Xu, A. Konstantinov, J. Amodeo, W. Jansen, A. Alajbegovic, "Simulation of Cooling Airflow under Different Driving Conditions," SAE 2007-01-0766, SAE World Congress, Detroit, April 2007

[11] S. Brémont, G. Servera, E. Fares, J. Abanto, A. Alajbegovic: "Experimental Investigation and Numerical Validation of Cooling Airflows of a Realistic Vehicle," $6^{\text {th }}$ FKFS Conference, Stuttgart, Germany, October 2007

[12] U. Frisch, B. Hasslacher, and Y. Pomeneau, "Lattice gas automata for the Navier-Stokes equation," Physical Review Letters, 56:15051508, 1986.

[13] S. Chen and G. D. Doolen, "Lattice Boltzmann method for fluid flows", Annual Review of Fluid Mechanics, 30:329-364, 1998.

[14] S. Succi, The Lattice Boltzmann Equation for Fluid Dynamics and Beyond, Series Numerical Mathematics and Scientific Computation, Clarendon Press, Oxford, 2001. 
[15] D. d'Humieres, P. Lallemand and Y. H. Quian, "Lattice BGK models for NavierStokes equations," Europhysics Letters, 17(6):479-484, 1992.

[16] V. Yakhot, and S.A., Orszag, "Renormalization Group Analysis of Turbulence. I. Basic Theory" J. Sci. Comput., 1(2), 3-51, 1986.

[17] V. Yakhot, V., S.A. Orszag, S. Thangam, T. Gatski, and C. Speziale, "Development of turbulence models for shear flows by a double expansion technique," Phys. Fluids A, 4 (7), 1510-1520, 1992.

[18] H. Chen, S.A. Orszag, I. Staroselsky, and S. Succi, "Expanded Analogy between Boltzmann Kinetic Theory of Fluid and Turbulence", J. Fluid Mech., 519: 307-314, 2004.

[19] H. Chen, "H-theorem and generalized semidetailed balance conditions for lattice gas systems," J. Stat. Phys. 81:347-359, 1995.

[20] H. Chen and C. Teixeira, "H-Theorem and origins of instability in thermal lattice Boltzmann models," Comp. Phys. Communication, 129:21-31, 2000.

[21] H. Chen and R. Zhang, "Lattice Boltzmann method for simulations of liquid-vapor thermal flows," Phys. Rev. E67(6): Art. no. 066711 Part 2, 2003.

[22] C. M. Teixeira, "Incorporating turbulence models into the lattice-Boltzmann method," Int. J. Modern Physics C, 9(8):1159-1175, 1998.

[23] PowerFLOW User's Guide, Release 4.1, Exa Corporation, Boston, Massachusetts, 2007.

[24] Dymola User's Guide, Release 7.2, Dynasim AB, Lund, Sweden, 2009.

[25] www.Modelica.org, accessed August 2009

[26] S.E., Mattsson, H. Elmqvist, M. Otter, "Physical system modeling with Modelica," Control Engineering Practice, 6, 501-510, 1998.

[27] D. Limperich, M. Braun, G., Schmitz, and K. Prölß, "System Simulation of Automotive Refrigeration Cycles," $4^{\text {th }}$ International Modelica Conference, Hamburg, 2005.

[28] H. Tummescheit and D. Limperich, "The AirConditioning library for simulation of advanced vehicle A/C systems," VTMS8: Vehicle Thermal Management Systems Conference \& Exhibition, Nottingham, 2007. 